\title{
Dielectric Properties of Vegetable Oils
}

\author{
Z. H. Shah* and Q. A. Tahir \\ Department of Basic Sciences, School of Science and Technology, University of Management and \\ Technology, C-II Johar Town, Lahore-54770, Pakistan
}

Received 11 February 2011, accepted in final revised form 19 May 2011

\begin{abstract}
In search of PCB (polychlorinated biphenyl) free mineral oil used in transformer, we have carried out the detailed study on dielectric properties of some vegetable oils, such as corn oil and cottonseed oil. Dielectric constant, dielectric loss factor have been determined for corn oil, cotton seed oil, and PCB free mineral transformer oil having International Electrotechnical Commission number IEC-60296 in the frequency range $330 \mathrm{~Hz}$ to $3 \mathrm{MHz}$ and in temperature range $25^{\circ} \mathrm{C}$ to $70^{\circ} \mathrm{C}$. The dielectric data of the vegetable oils is critically compared with that of the transformer oil and appropriate causes for similarities and differences have been discussed. Owing to comparable results in the vegetable oils and transformer oil studied, it is suggested that vegetable oils may also be used as transformer oil.
\end{abstract}

Keywords: dielectric constant; dielectric loss; dielectric relaxation; polarization.

(C) 2011 JSR Publications. ISSN: 2070-0237 (Print); 2070-0245 (Online). All rights reserved.

doi:103329/jsr.v3i3.7049 J. Sci. Res. 3(3), 481-492 (2011)

\section{Introduction}

Distribution transformer selection, whether for residential, commercial, industrial, or utility application, has long-term ramifications. Transformers can have lives of 15, 30, and even 50 years or more, depending on their design, loading, application, protection, and maintenance. It is important to evaluate all of the transformer attributes that affect the purchase decision. Liquid-filled transformers are often not considered as an option for indoor installations when they should be due to historical issues of fire safety, environmental concerns, and special containment. Because of these perceptions, vacuum pressure impregnated (VPI) dry-type and cast-resin transformers have often replaced liquid-filled transformers for indoor and adjacent to building installations [1]. With this trend, significant liquid filled advantages have been lost like superior life, efficiency, sound level, overload capacity, contamination resistance, and online diagnostics. Changes

\footnotetext{
* Corresponding author: zaheer.hussain@umt.edu.pk
} 
in the transformer fluids and listing requirements now overcome the fire safety and environmental issues so that the benefits of liquid-filled transformers can be retained for indoor and adjacent to building installations.

Since the 1970s, the public has been sensitized to the polychlorinated biphenyl (PCB) based transformer oils. In 1976, the Toxic Substance Control Act [2] targeted PCB. The banning of further production and commercialization of PCBs, and increasingly restrictive Federal and state regulations, led to the introduction of other fire-resistant transformer types. While most PCB oil filled transformers have been replaced with PCB free mineral oil, fire resistant hydrocarbon fluids, or silicone oil, the replacement fluids have still not been environmentally preferred. The U. S. Environmental Protection Agency (EPA) published its most recent changes in 1998[3]. Cooper Power Systems (CPS) developed a fire resistant natural ester based dielectric coolant [4]. In addition to superior fire safety, these natural ester dielectric fluids meet the US Environmental Protection Agency criteria as having "ultimate biodegradability" [5].

It is increasingly important that dielectric fluids provide a better balance of functional performance inside the transformer versus environmental impact in the event of release. Inside the transformer, a stable, chemically inert fluid having good thermal and dielectric properties is desired. Externally, the fluid should become environmentally benign by being non-toxic and readily biodegradable. The environmental properties of vegetable oils are excellent.

Vegetable oils biodegrade quickly and completely, and also exhibit very low or no toxicity as compared to mineral oils [6]. This is mainly due to the fact that vegetable oil dielectric fluids do not contain halogens, polynuclear aromatics, volatile or semi-volatile organics, or other compounds that can be present in mineral oils or other dielectric fluids [7]. Vegetable oils have a much better biodegradation capacity than mineral oil under aerobic as well as anaerobic conditions. Tests carried out by various researchers severally indicate that vegetable oils undergo about $70-100 \%$ biodegradation in a period of 28 days [8]. Significantly, they are environmentally friendly: renewable, non toxic and biodegradable [6].

Natural esters have the highest chemical and thermal stability. Natural ester dielectric fluids have a fire point of $360^{\circ} \mathrm{C}$ and qualify as "K" class per IEC 61100 . They have practical installation and regulatory advantages in many types of sites [9-11]. A series of experiments establish that the thermal degradation of paper insulation decreases by a factor of 5-8 times in natural ester compared to the degradation in mineral oil [12-14]. Vegetable oils show some oxidative stability as well. The products of oxidation in mineral oil can react to form sludge precipitates. However, vegetable oils oxidize differently than mineral oils. The products of oxidation do not form sludge precipitates. Instead, the oil eventually begins to thicken and ultimately polymerize [15]. This results in dramatic increase in viscosity which may form the basis of a "smart" self sealing system for cable applications. Different researchers have reported the general indicators of oil ageing, for example, coloration [16], oxidation [17], increased acid number, water content [18] and increased dielectric loss [19] are well understood and appreciated. Hosier et al, 2008[20] 
reported that the dielectric loss of vegetable oils ofter any given period of ageing was no worst than mineral oil and hence they could form the basis of suitable replacement for mineral oil in high voltage equipments.

Vegetable oils are used in transformers due to their electrical insulating property that becomes limited by their breakdown on the application of high voltage across them. This breakdown voltage is highly influenced by the impurities like humidity, gases and particles present in the oil. This gives rise to the tendency for comparing them with others by controlling the impurity contents. Water solubility level of ester and mineral oil creates a great difference between them. Ester oil is capable of absorbing 20 to 30 times more water than mineral oil that decreases the humidity effect on insulation strength of ester oil [21]. This makes the ester oil superior than mineral oil. But on the other hand, one should be very careful in handling the ester oils when used in transformer.

Fire-resistant natural ester fluids have redefined the liquid insulated transformer value proposition. Consultants, engineering firms, contractors, and end-users are rethinking their transformer selection based on the many benefits of using liquid- filled transformers indoors. Since the introduction of ester-based fluids five years ago, dozens of indoor applications are leading the way to restoring these advantages at the lowest first cost and lowest operating costs. New fluid insulation technologies preserve and improve on the performance advantages of liquid-filled designs while providing excellent environmental and safety benefits [1].

This work deals with the measurement of dielectric properties of edible oils (in the category of Natural Ester Fluid) such as corn oil and cottonseed oil, and transformer oil (in the category of Mineral Oil). From table (given below), it is clear that the edible oils seem to be superior to the transformer oil as for as various attributes are concerned. The relative comparison of high fire point and less flammable liquid filled transformer types, and their attributes are given in Table 1 below [22].

Table 1. Relative comparison of high fire point and less flammable liquid filled transformer types, and their attributes.

\begin{tabular}{|c|c|c|c|c|}
\hline Attributes & Mineral oil & Hydrocarbon oil & $\begin{array}{l}\text { Silicone } \\
\text { oil }\end{array}$ & $\begin{array}{l}\text { Natural ester } \\
\text { fluid }\end{array}$ \\
\hline Fire resistance & Poor & Excellent & Excellent & Excellent \\
\hline Environmental impact & Moderat & Moderate & Moderate & Excellent \\
\hline $\begin{array}{l}\text { Life expectancy at } \\
\text { maximum temp rating }\end{array}$ & Good & Good & Good & High \\
\hline Efficiency & High & High & High & High \\
\hline Sound level & Low & Low & Low & Low \\
\hline Operating temperature & Low & Low & Low & Low \\
\hline Contamination resistance & Excellent & Excellent & Excellent & Excellent \\
\hline Overload capacity & Good & Excellent & & Excellent \\
\hline First cost & Low & Low/Moderate & High & Moderate \\
\hline Energy costs & Low & Low & Low & Low \\
\hline Recycle/Disposal costs & Low & Low & High & Low \\
\hline
\end{tabular}




\section{Experimental Detail}

Three samples namely, corn oil, cottonseed oil and transformer oil (having International Electrotechnical Commission number IEC-60296) used in this experiment were purchased from the local market. The dielectric measurements were made by using an Ando TRS$10 \mathrm{~T}$ dielectric loss measurement system [23, 24]. Measured quantities were the capacitance $\mathrm{C}_{a}$ (air as a dielectric), the capacitance $C_{x}$ (oil as a dielectric) and the conductance $G_{x}$ of the dielectric at frequency $\omega=2 \pi f$ ( $\mathrm{f}$ is the measuring frequency of observation). These measurements were made in the frequency range, $330 \mathrm{~Hz}$ to $3 \mathrm{MHz}$ and temperature range $25{ }^{\circ} \mathrm{C}$ to $70{ }^{\circ} \mathrm{C}$ for all the three samples. The dielectric constant $\varepsilon$ and dielectric loss factor $\varepsilon^{\prime \prime}$ were calculated as [23, 24].

$$
\varepsilon^{\prime}=\frac{C_{x}}{C_{a}} \text { and } \quad \varepsilon^{\prime \prime}=\frac{G_{x}}{\omega C_{a}},
$$

where $C_{a}=\frac{(0.0885) A}{t}$, and $A$ is the area of electrode in $\mathrm{cm}^{2}$ and $t$ is the thickness of the specimen in $\mathrm{cm}$.

The measured data was recorded and plotted in such a way that the dots in figures represent the experimental results while straight lines are the result of the computer generated least square fit to the data. After finishing the measurements for each replicate, the oil sample was drained out from the test fixture, and then the fixture was disassembled, cleaned, and dried at room temperature.

The investigations of breakdown voltage of different oils are carried out in a cell with $10 \mathrm{~mm}$ diameter spherical electrodes with $2.5 \mathrm{~mm}$ gap. The voltage raised with a step of 5 $\mathrm{kV}$ until flash over is observed. The test was repeated 6 times as required by the IEC 60156 standard.

\section{Results and Discussion}

Fig. 1 shows the frequency dependence of dielectric constant $\dot{\varepsilon}$ for all three samples at room temperature. The comparison of dielectric constant values of corn oil and cottonseed oil with that of transformer oil shows that dielectric constant values of corn oil and cottonseed oil are higher than that of the transformer oil. The two vegetable oils have nearly the same dielectric constant which is relatively higher than that found in the transformer oil. This can be attributed to the presence of triglycerides in the vegetable oils which have a polar nature. On the other hand, transformer oil mainly consists of refined petroleum which contains non polar alkane molecule and thus it has a comparatively lower dielectric constant [25]. From Fig. 1, it is clear that the dielectric constant shows a slight decrease with frequency. Similar observations have been made in ref. [26, 27]. 


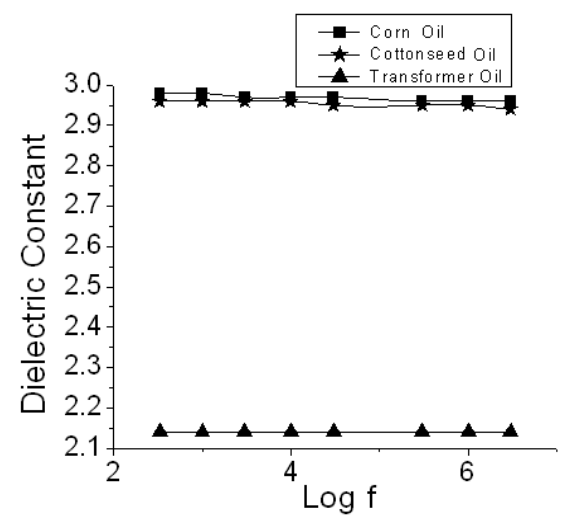

Fig. 1. Frequency dependence of dielectric constant for corn oil, cotton seed oil and transformer oil at $25{ }^{\circ} \mathrm{C}$.

As dielectric dispersion occurred, the dielectric spectra diminished and there is slight monotonous decrease of $\dot{\varepsilon}$ values of vegetable oils with the increase in frequency. This change is in accord with the Debye equations for dependence of the $\dot{\varepsilon}$ on frequency which show that $\dot{\varepsilon}$ decreases with frequency. This decreasing tendency is also in close agreement with earlier results [27] in which Pace et al. reported that the $\varepsilon$ of selectively hydrogenated vegetable shortening showed a general plateau in low frequency range and then a decrease as the frequency was further increased. Otherwise, the study of dielectric properties of oils in low frequency region will benefit the development of a simple and cheap method for evaluating oil quality. This change is only observed in vegetable oils due to the fact that dielectric medium have orientation polarization (also known as dipole polarization), atomic polarization and electronic polarization, where as in case of pure transformer oil (which contains non polar alkane molecule) there is no orientation polarization and $\varepsilon^{\prime}$ remains constant due to the contribution of only atomic and electronic polarization of transformer oil.
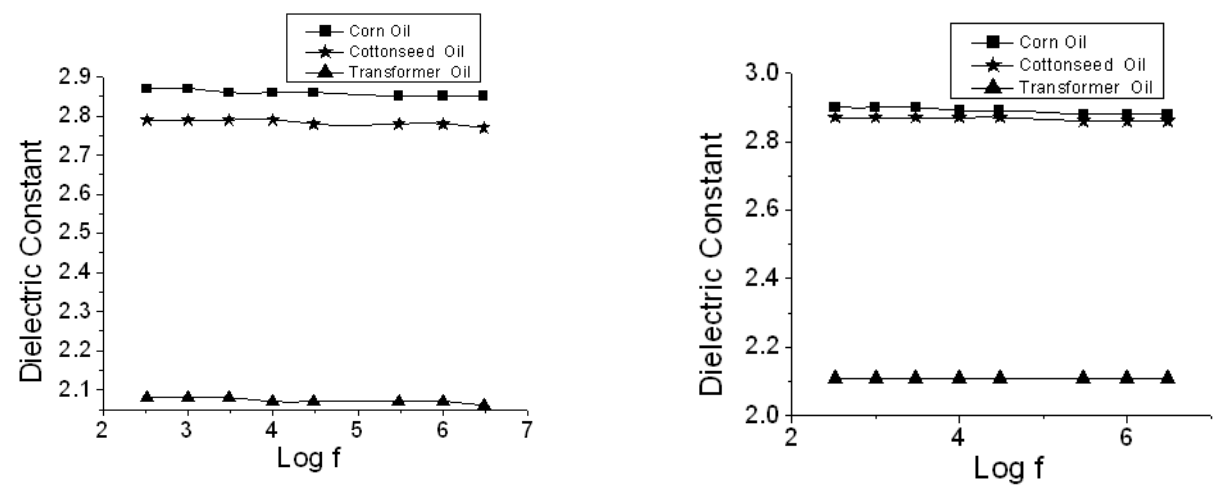

Fig. 2. Frequency dependence of dielectric constant for corn oil, cotton seed oil and transformer oil at (a) $50{ }^{\circ} \mathrm{C}$ (left) and (b) $70{ }^{\circ} \mathrm{C}$ (right) . 
Fig. 2 shows the frequency dependence of dielectric constant $\varepsilon$ for all three samples at elevated temperatures of $50{ }^{\circ} \mathrm{C}$ and $70{ }^{\circ} \mathrm{C}$. These figures show that there is a slight decrease in the dielectric constant with the increase in temperature. This decrease in dielectric constant with the increase in temperature is due to the decrease in density which is directly related to the density of dipoles in the sample. The increase of temperature also causes the increase in kinetic energy of the moving segments leading to a greater randomness of motion and thus it decreases the dipole orientation which results in low dielectric constant.

Figs. 3 show the temperature dependence of dielectric constant $\dot{\varepsilon}$ for all the three samples at frequency of $3 \mathrm{kHz}, 30 \mathrm{kHz}$ and $1 \mathrm{MHz}$. From these figures, it is clear that the dielectric constant of all samples decreases with increase in the temperature. This temperature dependence of all oils could be assumed that, as the temperature increased, oil viscosity decrease, relaxation times decrease leading to an increase in dipole moment and a decrease in the $\dot{\varepsilon}$. It is well-known that the viscosity of oils decreases with the degree of un-saturation increasing. Therefore, it could be assumed that the different viscosity of oils resulted in the differences of decreased gradient of $\varepsilon$ of different oils with increasing temperature [26].
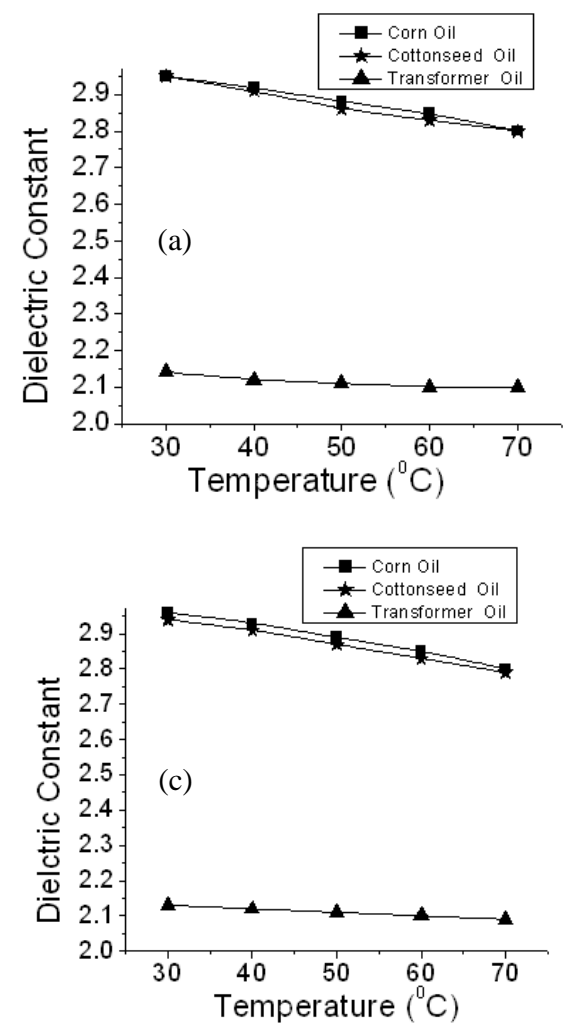

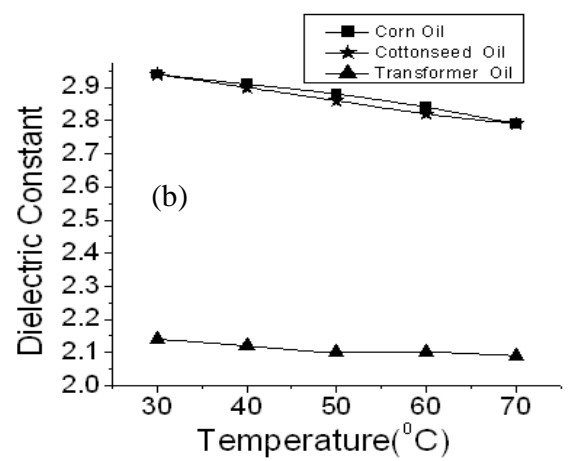

Fig 3. Temperature dependence of dielectric constant for corn oil, cottonseed oil and transformer oil at frequencyof (a) $3 \mathrm{kHz}$, (b) $30 \mathrm{kHz}$, and (c) $1 \mathrm{MHz}$. 
We use a dielectric coolant and fluid, having high dielectric constant for distribution and power transformers [28]. Comparison of the dielectric constant values of vegetable oils with that of transformer oil (as shown in Figs. 1-3) suggests that the vegetable oils having the higher value of dielectric constant may be used in transformers as a dielectric coolant.

Dielectric loss factors $\left(\varepsilon^{\prime \prime}\right)$ of two vegetable oils and transformer oil are measured over the frequency range $330 \mathrm{~Hz}-3 \mathrm{MHz}$ at three fixed temperatures, $25^{\circ} \mathrm{C}, 50^{\circ} \mathrm{C}$ and $75^{\circ} \mathrm{C}$. Figs. 4 show the results. The $\varepsilon^{\prime \prime}$ for insulating materials used in electrical equipment are constituted by two different components: the losses related to conduction processes and those related to the polarization phenomena. Since vegetable oils have polar nature and their conductance also increases with the rise in frequency at fixed temperature. So in vegetable oils conductance and polarization both factors increase $\varepsilon^{\prime \prime}$ at higher frequencies. Fig. 4a indicates that $\varepsilon^{\prime \prime}$ for the vegetable oils exhibited same frequency dependence, i.e., a decrease in $\varepsilon^{\prime \prime}$ from $330 \mathrm{~Hz}$ to $1 \mathrm{kHz}$ mainly due the increase in polarization effect which causes to increase in dielectric constant and eventually decreases $\varepsilon^{\prime \prime}$. After this $\varepsilon^{\prime \prime}$ have almost constant value up to $10 \mathrm{kHz}$ and finally an increase in $\varepsilon^{\prime \prime}$ from $10 \mathrm{kHz}$ due to the increase in conduction with rise in frequency. The transformer oil is a non-polar liquid with a capacitance that changes very little with frequency, but oil also has conductivity that varies with the frequency. The conductivity of transformer oil initially decreases with the rise of frequency so in Fig. 4a there is initially decrease in the $\varepsilon^{\prime \prime}$. At higher frequencies conductivity of the oil increases, this yields increase in the dielectric loss factor. Hence dielectric loss in good transformer oil at power frequencies and operating temperatures results from conduction only, the contribution of polar molecules to the $\varepsilon$ being negligible.
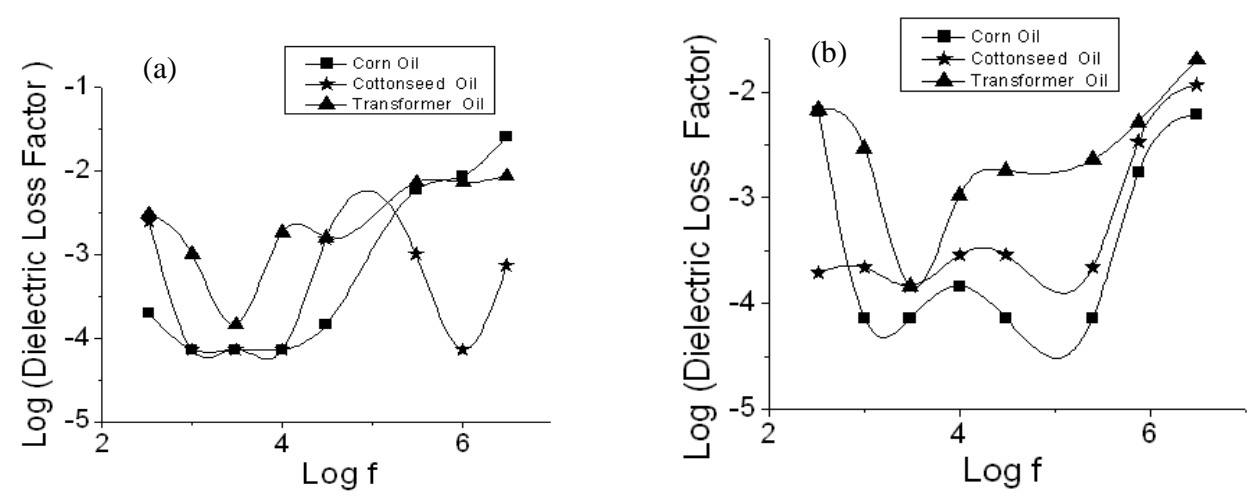


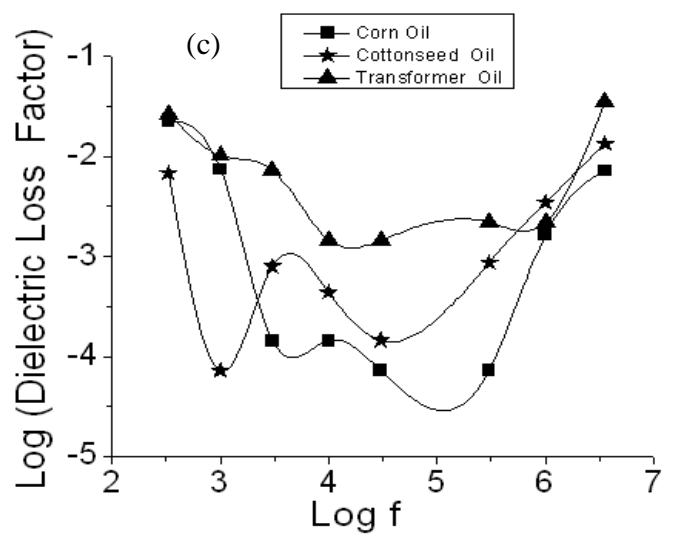

Fig. 4. Frequency dependence of dielectric loss factor for corn oil, cotton seed oil and transformer oil at temperature (a) $25^{\circ} \mathrm{C}$, (b) $50{ }^{\circ} \mathrm{C}$, and (c) $70{ }^{\circ} \mathrm{C}$.

When the same type of plots ( $\left.\varepsilon^{\prime \prime} v s . \log f\right)$ are taken at $50^{\circ} \mathrm{C}$ and $70^{\circ} \mathrm{C}$ (Figs. 4 b, c), it is seen that the transformer oil has same behavior, i.e, first its $\varepsilon^{\prime \prime}$ decreases due to decrease in conductance at lower frequency side and then $\varepsilon^{\prime \prime}$ is increasing as we go to higher frequency side due to the increase in conductance. For vegetable oil at higher temperatures $\left(50^{\circ} \mathrm{C}\right.$ and $\left.70^{\circ} \mathrm{C}\right)$ a small $\varepsilon^{\prime \prime}$ peak is observed at intermediate frequency, which may be attributed to the accumulation of free fatty acids or other impurities at the electrode surface. This effect is more enhanced at higher temperatures due to the lower viscosity of the medium.

The temperature dependence of $\dot{\varepsilon}$ and $\varepsilon^{\prime \prime}$ is quite complex and may increase and decrease with temperature at fixed frequency depending on the material. For transformer oil before and after $3 \mathrm{kHz}, \varepsilon^{\prime \prime}$ increases. When $\log \left(\varepsilon^{\prime \prime}\right) v s$. $T$ scan is taken at this frequency as shown in Fig. 5a, it is seen that loss factor first decreases with increase in temperature. This is due to the fact that with the rise in temperature viscosity of the oil decreases due to which $\varepsilon^{\prime \prime}$ also decreases. As the temperature increases further the resistivity of the oil increases with the result in the fall of dielectric constant [29] and hence the increase in $\varepsilon^{\prime \prime}$. There is also a fluctuation in the $\varepsilon^{\prime \prime}$ for edible oils but $\varepsilon^{\prime \prime}$ for both cotton seed oil and corn oil is much lower than transformer oil. This shows that dielectric constant for edible oils has higher value than transformer oil at $3 \mathrm{kHz}$. When same plots are taken at $30 \mathrm{kHz}$ as shown in Fig. 5 b, it is seen that for transformer oil $\varepsilon^{\prime \prime}$ is greater as compared to edible oil and there is a small fluctuation in $\varepsilon^{\prime \prime}$ with the increase in temperature. When same plot is taken at $1 \mathrm{MHz}$ as shown in Fig. $5 \mathrm{c}$, it is seen that $\varepsilon^{\prime \prime}$ is small for transformer oil as well as edible oil but the value of $\varepsilon^{\prime \prime}$ is very small for edible oil as compared to transformer oil. 

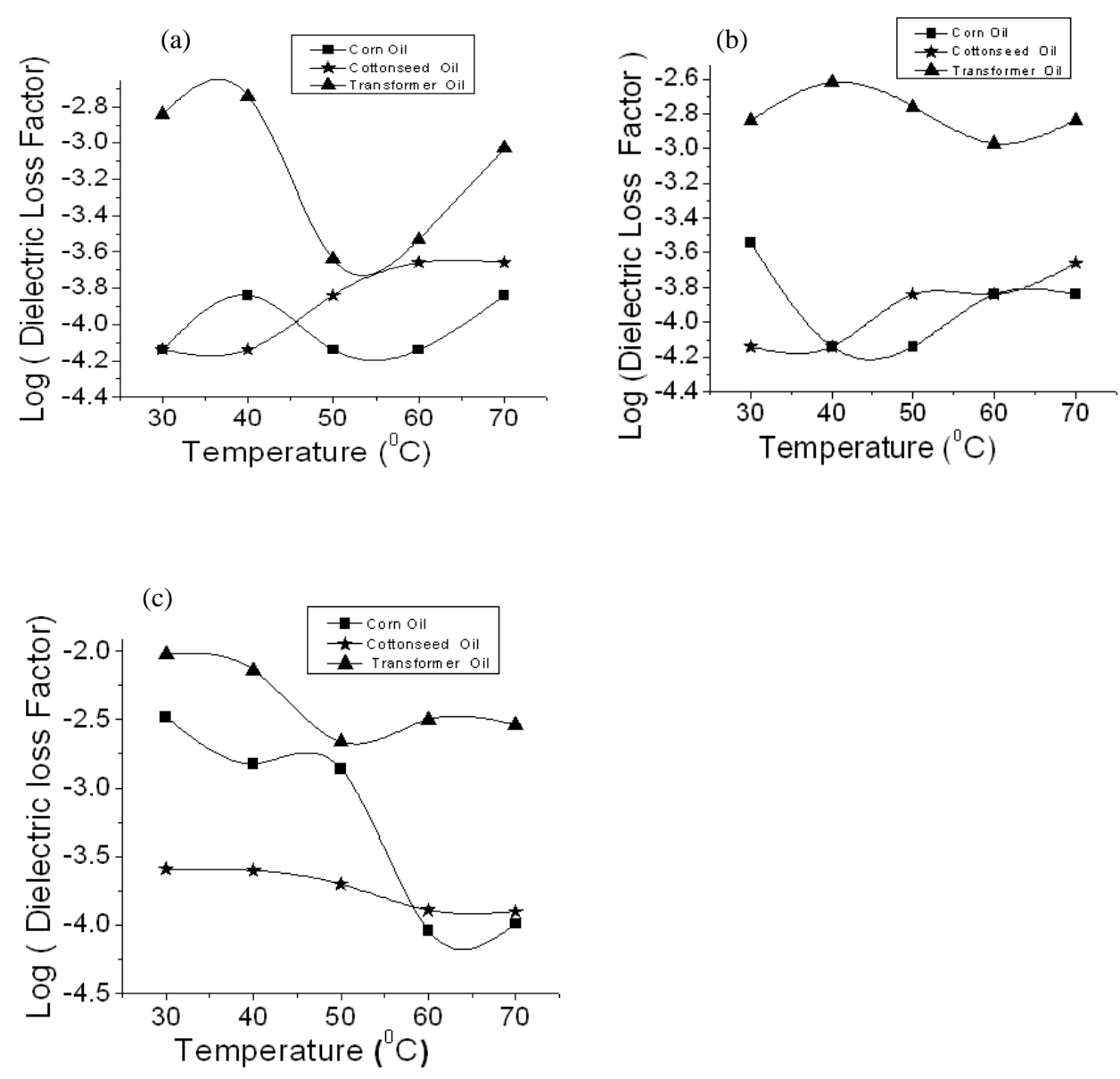

Fig. 5. Temperature dependence of dielectric loss factor for corn oil, cotton seed oil and transformer oil at frequency of (a) $3 \mathrm{kHz}$, (b) $30 \mathrm{kHz}$, and (c) $1 \mathrm{MHz}$.

In general, the dielectric loss factor of the two vegetable oils is less than that of transformer oil, particularly in corn oil (as shown in Figs. 4 and 5) over a wide frequency range. We use a dielectric coolant and fluid, having low value of dielectric loss factor for distribution and power transformers [30]. Comparison of the dielectric loss factor values of the vegetable oils with that of transformer oil suggests that the vegetable oils may be used in transformers because the loss factor is even lower than that in the transformer oil, generally at all frequencies and temperatures.

The results obtained from the experiment on breakdown voltage of oils are shown in Fig. 6. 


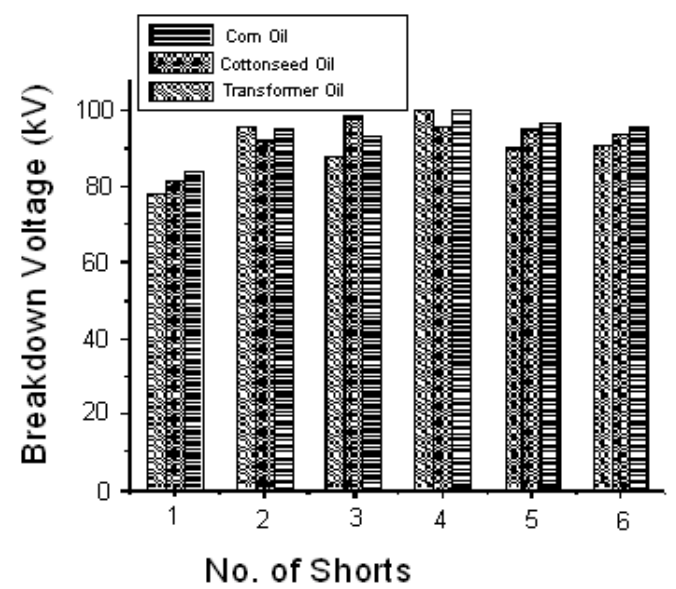

Fig. 6. Measurements of the breakdown voltage of oils with spherical electrodes with $2.5 \mathrm{~mm}$ gap.

The results show that the natural ester oils, especially corn oil, have somewhat better average BDV, which is $95 \mathrm{kV}$, than the mineral oils. But due to the steps of $5 \mathrm{kV}$ the true breakdown voltage may be $5 \mathrm{kV}$ less than the $95 \mathrm{kV}$ average observed values.

\section{Conclusions}

The market and regulatory pressures to reduce liability risk exposure of mineral-oil-filled distribution and power transformers are increasing. In addition, there are demands to improve equipment efficiencies and adopt more "earth-friendly" options in our power systems. Considering these paradigm shifts, the industry has been developing new transformer concepts.

The $\varepsilon$ of vegetable oils showed the same frequency dependence. The dielectric spectra exhibited a general plateau. As dielectric dispersion occurred, the dielectric spectra diminished and there is slight monotonous decrease of $\dot{\varepsilon}$ values of vegetable oils with the increase in frequency. The $\varepsilon \dot{\varepsilon}$ of transformer oil remains constant due to the presence of non polar alkane molecule but it decreases with increase in temperature. The results showed that the $\varepsilon$ value of vegetable oils has higher value and dielectric loss factor $\varepsilon^{\prime \prime}$ of vegetable oils have lower value than that of the transformer oil. The study of breakdown voltage of oils shows that, vegetable oils, especially corn oil, have somewhat better average value of breakdown voltage than that of the transformer oil.

Based on data obtained from laboratory experiment, it is suggested that a practical vegetable oil based dielectric coolant using food-grade additives may also be incorporated into transformer insulation systems with minimal modifications. 


\section{Acknowledgements}

The authors would like to thank the technical contribution of Pakistan Council of Scientific and Industrial Research (PCSIR), Laboratories, Lahore, Pakistan and University of Management and Technology, Lahore, Pakistan. Thanks are also due to Prof. Ehsan Ellahi Khawaja for his constant encouragement.

\section{References}

1. J. Piel, Electrical Line 11 (1), 40 (2005).

2. Toxic Substance Control Act, U.S. Environmental Protection Agency, Public Law (1976) pp. 94-469.

3. Disposal of Polychlorinated Biphenyls (PCB's), U.S. Environmental Protection Agency, 40 CFR, Federal Register (1998) pp. 750-761.

4. C. P. McShane, IEEE Trans. on Industry Applications, 37 (4) (July/August 2001) pp. 11321139, No. 0093-9994/01.

5. The Environmental Technology Verification Program, U.S. Environmental Protection Agency, Washington, DC, VS-R-02-02 (June, 2002). [Online] http://www.epa.gov/etv/pdfs/vrvs/06 vs cooper.pdf

6. L. A. T. Honary, Biodegradable/Biobased Lubricants and Greases, Machinery Lubrication Magazine Issue No. 200109, Noria Corporation, (2004) www.oilmaintenance.com.

7. S. Howell, Promising Industrial Applications for Soybean Oil in the US (2007).

8. P. Broekhuizen, D. Theodor, K. Le Blanch, and S. Ullmer, Lubrication in Inland and Coastal Water Activities (A. A. Balkema Publishers, Tokyo, 2003).

9. Transformer Fire Protection, Facilities Instructions, Standards, and Techniques, Vol. 3-32, Hydroelectric Research and Technical Services Group, Bureau of Reclamation, U.S. Dept. of Interior (Denver, CO USA, Jan., 2005).

10. 5-4 Transformers, Section 2.3.1.1.1 Separation Distance, Property Loss Prevention Data Sheets, Factory Mutual Global, May (2003), Norwood, MA USA.

11. Classification of insulating liquids according to fire-point and net calorific value, CEI/IEC 61100: 1992-05, International Electrotechnical Commission, p. 11 (2005), Geneva, Switzerland.

12. C. P. McShane, K. J. Rapp, J. L. Corkran, G. A. Gauger, and J. Luksich, Aging of Paper Insulation in Natural Ester Dielectric Fluid, EEE/PES Transmission \& Distribution Conference, Oct. 28 - Nov. 2, (2001), Atlanta, GA USA.

13. C. P. McShane, K. J. Rapp, J. L. Corkran, and J. Luksich, Aging of Cotton/Kraft Blend Insulation Paper in Natural Ester Dielectric Fluid, Tech Con 2003 Asia Pacific, May 7-9, (2003), Sidney, Australia.

14. C. P. McShane, J. L. Corkran, K. J. Rapp, J. Luksich, Aging of paper insulation retrofilled with natural ester dielectric fluid. In: IEEE/DEIS Conference on Electrical Insulation and Dielectric Phenomena, Oct. 19-22, (2003), Albuquerque, NM USA.

15. Standard Specification for Natural (Vegetable Oil) Ester Fluids Used in Electrical Apparatus, ASTM D6871-03, ASTM International, West Conshohocken, PA USA.

16. R. Ferguson, A. Lobeiras, and J. Sabau, IEEE Electr. Insul. Mag. 18 (4), 17 (2002). doi:10.1109/MEI.2002.1019902

17. R. Blue, D. Uttamchandani, and O. Farish, IEEE Trans. Diel. Electr. Insul. 5, 165 (1998). doi:10.1109/94.671924

18. T. O. Rouse, IEEE Electr. Insul. Mag. 14, 6 (1998). doi:10.1109/57.675572

19. M. Kanno, N. Oota, T. Suzuki, and T. Ishii, IEEE Trans. Diel. Electr. Insul. 8, 1048 (2001). doi:10.1109/94.971464 
20. I. L. Hosier, A. S. Vaughn, and S. G. Swingler, Studies on the ageing behavior of various synthetic and natural insulation oils. In: IEEE International Conference on Dielectric liquids, 29 June - 4 July (2008).

21. A. Darwin, C. Perrier, and P. Foliot, The Use of Natural Ester Fluids in Transformers. In: Proceedings of MATPOST conference, Lyon (France), Paper 0036 (November 15-16, 2007).

22. J. Piel and J. Corkron, Electricity Today, 16 (8), 28 (2004).

23. Instruction Manual for type TR-10C, Dielectric Loss Measuring set, Ando Electric Co. Ltd., Japan (1982).

24. Instruction Manual for type SE-70, Electrode Ando Electric Co Ltd, Japan (1982).

25. A. Javed, M. Akram, and M. Imtiaz, Rom. J. Phys. 51 (7-8), 819 (2006).

26. Hu Lizhi, K. Toyoda, and I. Ihara, J. Food Engineering 88, 151 (2008).

27. W. Pace, W. B. Westphal, and S. A. Goldblith, J. Food Science 33, 30 (2006). doi:10.1111/j.1365-2621.1968.tb00879.x

28. M. J. Heathco, The J \& P Transformer Book: a practical technology of the power transformer, Technology and Engineering, 13 ${ }^{\text {th }}$ edition (2007) p. 62.

29. E. V. Shatokhina, Chemistry and Technology of Fuels and Oils 43, 5 (2007).

30. H. P. Bloch (ed.), Practical Lubrication for Industrial Facilities, $2^{\text {nd }}$ edition (Fairmont Press, USA, 2009) p. 47. 